\title{
Predicting Emergency Dental Care over a Decade: Investigating Dental Care-Related Fears in Symptomatic Treatment-Seeking Behavior
}

\author{
Cameron L. Randall \\ West Virginia University
}

Follow this and additional works at: https://researchrepository.wvu.edu/etd

\section{Recommended Citation}

Randall, Cameron L., "Predicting Emergency Dental Care over a Decade: Investigating Dental Care-Related Fears in Symptomatic Treatment-Seeking Behavior" (2012). Graduate Theses, Dissertations, and Problem Reports. 3500.

https://researchrepository.wvu.edu/etd/3500

This Thesis is protected by copyright and/or related rights. It has been brought to you by the The Research Repository @ WVU with permission from the rights-holder(s). You are free to use this Thesis in any way that is permitted by the copyright and related rights legislation that applies to your use. For other uses you must obtain permission from the rights-holder(s) directly, unless additional rights are indicated by a Creative Commons license in the record and/ or on the work itself. This Thesis has been accepted for inclusion in WVU Graduate Theses, Dissertations, and Problem Reports collection by an authorized administrator of The Research Repository @ WVU. For more information, please contact researchrepository@mail.wvu.edu. 
Predicting Emergency Dental Care over a Decade:

Investigating Dental Care-Related Fears in Symptomatic Treatment-Seeking Behavior

\author{
Cameron L. Randall
}

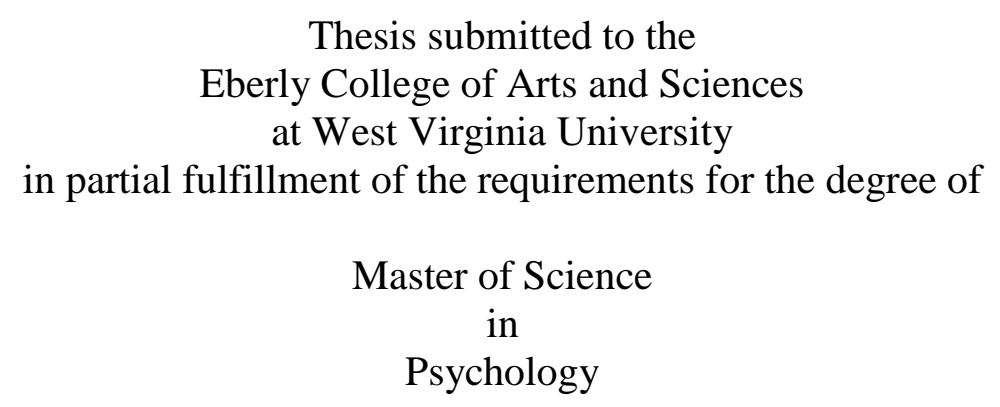

Daniel W. McNeil, Ph.D., Chair

Aaron Metzger, Ph.D.

Robert N. Stuchell, D.M.D.

Department of Psychology

Morgantown, West Virginia

2012

Keywords: behavioral dentistry; symptomatic care; fear; anxiety; pain

Copyright 2012 Cameron L. Randall 


\begin{abstract}
Predicting Emergency Dental Care over a Decade:

Investigating Dental Care-Related Fears in Symptomatic Treatment-Seeking Behavior
\end{abstract}

\author{
Cameron L. Randall
}

Avoidance of dental care, resulting from fear and anxiety, has major implications for oral and overall health. For instance, untreated oral disease may exacerbate cardiovascular disease and diabetes, among other systemic health concerns (Williams et al., 2008). In the USA, 5-10\% of adults avoid necessary dental treatment because of dental care-related fear (Milgrom et al., 2009). The long-term goal of this project was to improve our understanding of psychosocial barriers to oral health care. Specifically, the study aimed to examine the relation between dental care-related fears, fear of pain, and dental beliefs in a rural, Appalachian population and to determine the impact and mechanism of the role of dental care-related fear and anxiety in the long-term utilization of an emergency dental clinic. For this retrospective cohort study, participants were 80 (40 female) adults visiting the West Virginia University School of Dentistry emergency clinic. A decade ago, these patients completed the Dental Fear Survey, the Fear of Pain Questionnaire, and the Dental Beliefs Scale in addition to a demographic questionnaire. Ten-year follow-up of these patients was completed by way of dental chart review. Abstracted information about the frequency and nature of emergency clinic visits was compared to the previously completed measures of dental care-related fear and anxiety using multiple linear regression analysis; neither dental care-related fear, fear of pain, nor negative beliefs about dentistry predicted total number of clinic visits or extractions for this sample of symptomatic treatment seekers. Interestingly, patients who received restorative dental treatment versus extractions had completed a significantly greater number of years of education than those who did not receive restorative treatment. Future work should continue to address symptomatic treatment-seeking patients, as they are a unique population whose dental attendance patterns may benefit from psychosocial intervention. 
Table of Contents

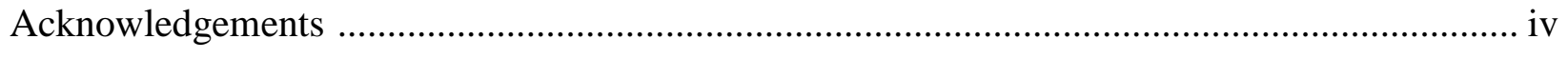

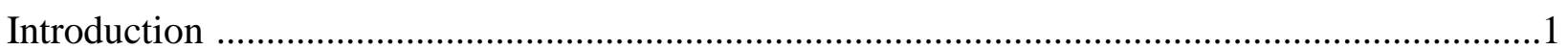

Symptomatic and Asymptomatic Treatment-Seeking Behavior in Dental Patients ..................1

Defining Dental Care-Related Fear and Anxiety ............................................................

Etiology of Dental Care-Related Fear and Anxiety ..........................................................4

Patient Beliefs about Dentists and Dental Treatment .....................................................

Classification of Dentally Fearful/Anxious Patients .....................................................

Prevalence of Dental Care-Related Fear and Anxiety and Impact on Treatment Seeking .........9

Implications for Psychological and Physical Health .....................................................10

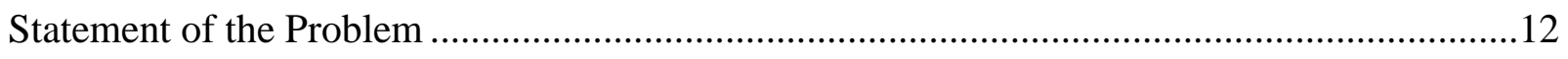

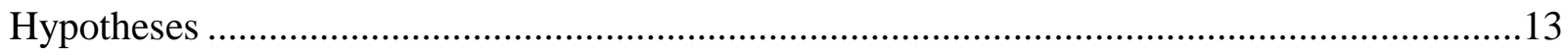

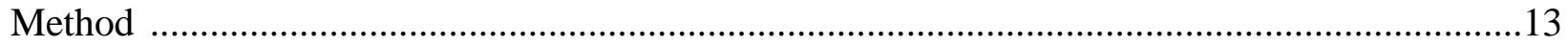

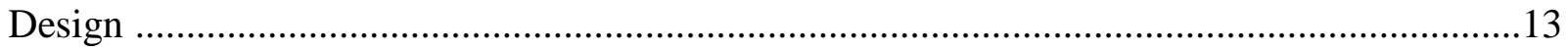

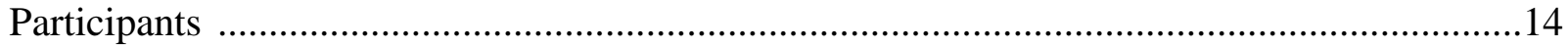

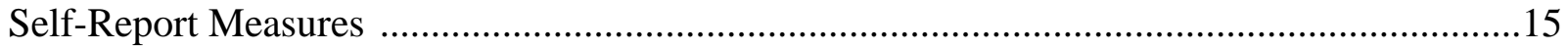

Demographic and General Dental Information Questionnaire .....................................15

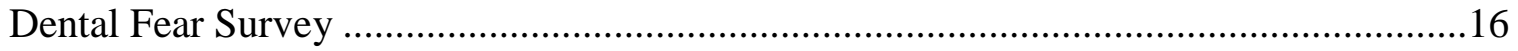

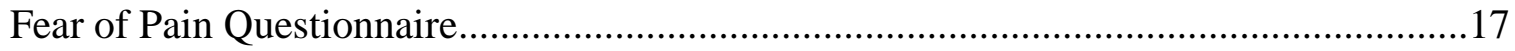

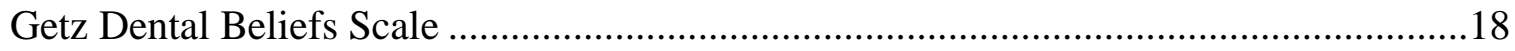

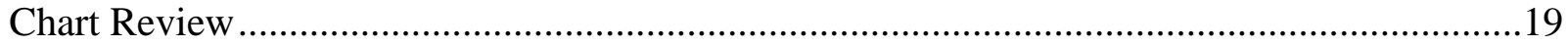

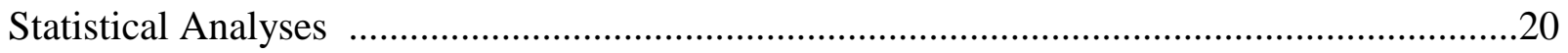

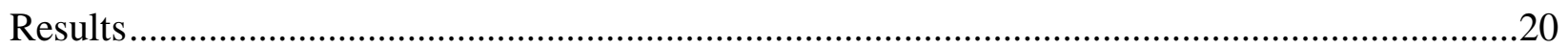

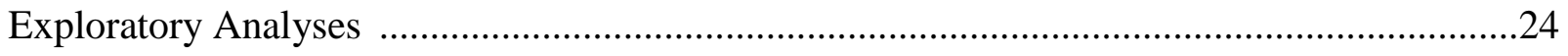

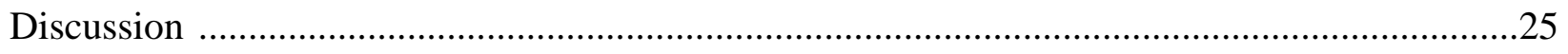

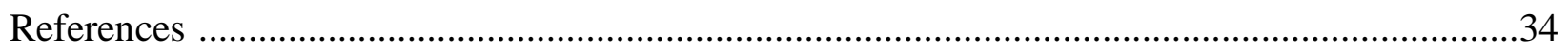

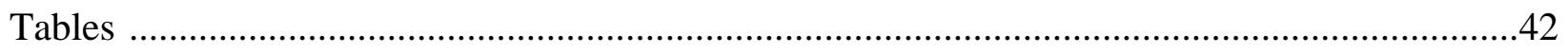

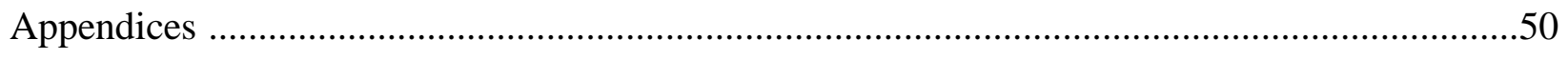

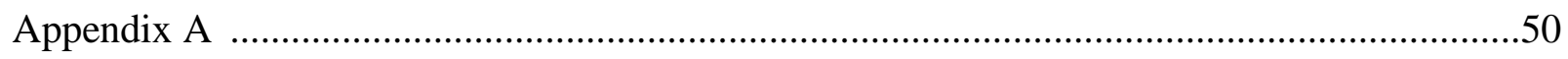

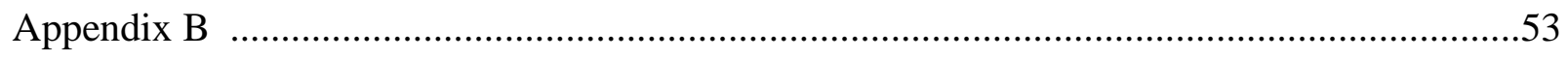

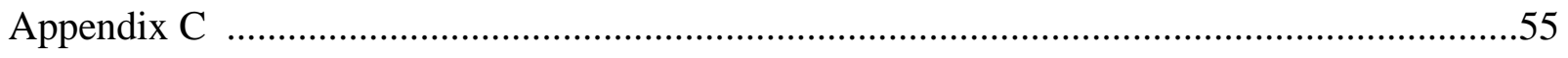

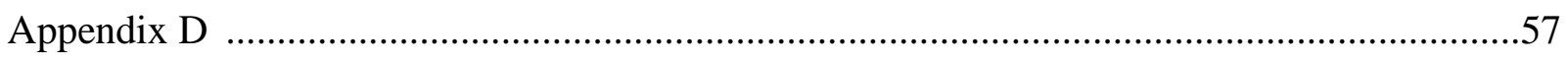

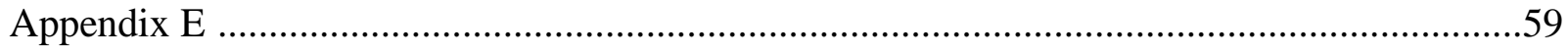

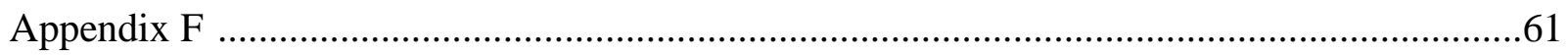




\section{Acknowledgements}

Completion of this project has been a rewarding experience that has included many unique and impactful opportunities. I am deeply appreciative of the time and guidance provided by the members of my thesis committee, Aaron Metzger, Daniel McNeil, and Bob Stuchell. Aaron's assistance with data review and statistical analyses was valuable and an informative part of my graduate education. Bob's knowledge of the West Virginia University School of Dentistry and his assistance with data collection was critical to the success of this project. The thesis committee's chair, my mentor and good friend, Dan McNeil deserves special gratitude. I appreciate Dan's expertise in behavioral dentistry, our inspiring and edifying discussions about science, and, most importantly, his constant, caring attention, support, motivation, and friendship. Sincere thanks to my great advisor.

I also express gratitude to a dear member of the Anxiety, Psychophysiology, and Pain Research Laboratory, Grant Shulman. Grant is one of the most helpful, talented, and hardworking undergraduate students I have known. It was a pleasure to work with him on this project and I am appreciative of his assistance with data collection. Additionally, I am thankful for the support of my classmates - I have enjoyed sharing in this experience with them and have enjoyed stimulating discussions about psychology, research, and graduate student life.

I am also thankful for the opportunities to have presented some of the most interesting findings of this project locally, nationally, and internationally. I am appreciative of the support I received from the American Association for Dental Research, the International Association for Dental Research, and the Society of Behavioral Medicine. I am especially grateful of the opportunity I had to present this research to students and faculty of the West Virginia University 
School of Dentistry, the people who have a real connection to the data. Thanks to Richard Crout for that invitation.

Lastly, I must acknowledge the love and support that I have received from my family. To David and Debbie Randall, my parents, and Alyssa, my sister: Thank you! My family has been such a source of positivity, energy, and motivation, which has made my journey possible. I know that the journey will continue, and I look forward to it with great curiosity and enthusiasm! 


\section{Predicting Emergency Dental Care over a Decade:}

Investigating Dental Care-Related Fears in Symptomatic Treatment-Seeking Behavior

Dental care-related fear and anxiety are common and important barriers to dental treatment. In the USA, $45 \%$ of the population report at least moderate levels of dental carerelated fear (Dionne, Gordon, McCullagh, \& Phero, 1998). Not surprisingly, between 5 and 10 percent of adults avoid necessary treatment because of this fear (Milgrom, Weinstein, \& Heaton, 2009). Though dental care-related fear and anxiety, and their associated outcomes, are relatively well-studied, there certainly are gains to be made in our conceptualization of the construct. If these psychosocial barriers to oral health are to be reduced, there must be a better understanding of the constructs, their role(s) in treatment-seeking behaviors, and the most effective approaches to intervention.

\section{Symptomatic and Asymptomatic Treatment-Seeking Behavior in Dental Patients}

Utilizing dental care is highly individual, based on a variety of environmental (e.g., access/availability of care) and psychosocial (e.g., socioeconomic status, dental fear and anxiety) factors. Patients may follow a dentist's recommendation to visit the clinic at least twice each year for oral prophylaxes (dental cleanings) or other preventative treatment. This regular dental hygiene treatment has been cited as a critical factor in the reduction of oral disease (Nathe, 2005). Still, some patients may visit the dentist only when they perceive a dental emergency, such as when a dental problem becomes incredibly uncomfortable, painful, or visible. This "emergency," or symptomatic, treatment-seeking pattern is quite common. For instance, in the USA, only $64 \%$ of adults aged 18-64 visited the dentist within the last year (Fehrenbach \& Weiner, 2009). In a study by Davis, Deinard, \& Maiga (2010), emergency rooms in the Minneapolis-St. Paul metropolitan area saw over 10,000 visits for dental-related problems over a 
one-year period, with charges reaching almost $\$ 5$ million. The patients who accessed emergency treatment on this symptomatic basis reported that, even with treatment, the underlying dental problem usually was not resolved (Davis et al., 2010).

Individuals who seek dental care only in cases of a perceived or actual emergency may be at a greater risk for having poor oral health. Though the group certainly is highly diverse, symptomatic attenders generally are at higher risk for developing oral disease as a function of limited delivery of regular preventative treatment (Nathe, 2005). These patients have been shown to have a greater number of extracted teeth and fewer sealed teeth than those who attend dental visits asymptomatically (Hawley, Holloway, \& Davies, 1997). Clearly, then, pattern of dental attendance behavior is a critical component of oral health.

A host of determinants have been hypothesized for the observed differences in dental visit attendance patterns. To begin, the ability to access care impacts treatment-seeking behavior. Geographical location and socioeconomic status are factors that may affect an individual's ability to access dental care and, as might be expected, access to dental care has been shown to vary across gender, race, income, and education level (Mason, 2005). Additionally, research has demonstrated that general health status and acquisition of dental insurance impact dental treatment-seeking behavior (Fehrenbach \& Weiner, 2009). These access-to-care factors are important, as access is a prerequisite for utilization. Also implicated as determinants for dental visit patterns are psychosocial factors, such as knowledge, family modeling, health values/beliefs/attitudes, helplessness, isolation or vulnerability, and fear/anxiety (Mason, 2005). These factors are important in considering the utilization of dental services. In the context of the proposed study, dental care-related fear and anxiety are psychosocial predictors of treatment-seeking patterns that are worth some additional attention. Armfield, 
Stewart, and Spencer (2007) determined that high dental fear was positively related to symptomatic dental clinic visiting behavior, most often driven by a need for the relief of pain.

Further, urgency of emergency care-seeking behavior has been found to be significantly positively associated with being dentally anxious (Luzzi, Jones, Spencer, \& Roberts-Thomson, 2009). That is, individuals with high levels of dental care-related fear and anxiety are more likely to be symptomatic clinic visitors. When successfully treated for their anxiety, people with dental care-related anxiety show an increase in asymptomatic dental visit attendance (Dailey, Crawford, Humphris, \& Lennon, 2001). It appears that dental care-related fear and anxiety affect not only how a patient views the dental treatment experience, but also when and how he or she accesses necessary treatment (Boyle, Newton, Heaton, Afzali, \& Milgrom, 2010).

\section{Defining Dental Care-Related Fear and Anxiety}

Dental patients may be fearful or anxious about any number of aspects of dental treatment including sounds, smells, dental instruments, injections, perceived lack of control, and associated pain or discomfort (de Jongh, Muris, ter Horst, van Zuuren, \& de Wit, 1994; Johnsen et al., 2003; McNeil \& Berryman, 1989). Broadly defined, dental care-related fear is a distressing, negative emotional response to these treatment-related stimuli, characterized by physiological responsivity, feelings of apprehension and/or dismay, and avoidance. Fear generally, including dental care-related fear, is robust, typically defined by immediate onset, and often involves a salient physiological component (Craske, 2003).

A related, though distinct, construct is dental care-related anxiety: a cognitive and emotional response to stimuli associated with oral health care. Anxiety typically involves thoughts and worries and, in regard to exposure to evocative stimuli, often occurs distally in time (Craske, 2003). Experiences of both fear and anxiety generally, including those which are dental 
in nature, lie on a continuum (McNeil, Vargovich, Turk, \& Ries, in press). At the extreme, the fear or anxiety response to dental treatment-related stimuli may be profound enough to meet Diagnostic and Statistical Manual of Mental Disorders-IV-TR criteria for Specific Phobia. A dental care phobia may very well, though not necessarily, be a component of the complete avoidance of any situation in which the stimuli might be encountered.

Though fear and anxiety are separate constructs, they will be treated as one for the purposes of this project. This is due, in part, to the fact that this longitudinal study utilizes data collected over 10 years ago, data which do not allow for a clean distinction between dental carerelated fear and dental care-related anxiety. This treatment of the constructs also makes conceptualization and discussion more parsimonious. Additionally, and as discussed later, it makes for the more valid and appropriate use of available dental fear assessment instruments.

\section{Etiology of Dental Care-Related Fear and Anxiety}

A number of hypotheses have been suggested to describe the etiology of dental carerelated fear and anxiety (e.g., Locker, Liddell, Dempster, \& Shapiro, 1999; Milgrom et al., 2009; Vassend, Roysamb, \& Nielsen, 2011). First, dental care-related fear and anxiety may be conditioned through previous painful or traumatic dental experiences (Weiner \& Sheehan, 1990). Kent (1997) suggests that classical conditioning may operate to form and strengthen a fear or anxiety response if an association is made between dental treatment-related stimuli and an aversive experience (i.e., one in which there is discomfort, pain, or feelings of lack of control). For example, a patient's uncomfortable encounter with dental treatment, in which there is a high level of pain experienced as a result of the restoration of a tooth, may produce a future anxiety about or fear response to the sound of a dental drill or the smell of a dental clinic. Locker et al. 
(1999a) found that individuals with childhood-onset dental care-related fear and anxiety were more likely to show an etiology based on this conditioning.

The two-factor theory of learning extends this conditioning-based hypothesis of dental care-related fear etiology to explain the avoidance response associated with fear of dental treatment. Under this model, a patient's conditioned fear of dental treatment-related stimuli is maintained as a result of their avoidance, since the avoidance response is reinforced by a decrease in fear/distress (as the patient no longer has to encounter what they fear; Bouton, 2007). Conditioning, then, may be responsible for a fear response that is maintained by avoidance. While certainly a strong hypothesis with theoretical and empirical support, classical and operant conditioning are not the only mechanisms by which dental-care related fear and anxiety can develop and be maintained.

A second hypothesis is that cognition is a key component in the development and maintenance of dental-care related fear and anxiety. Misperceptions, negative thoughts, and schemata related to danger or lack of control are common in individuals with anxiety disorders, particularly Specific Phobia. It follows, then, that patients with dental-care related fear and anxiety may harbor thoughts and attitudes that result in an overestimation of the likelihood of negative outcomes related to dental treatment, producing a fear or anxiety response to the dental situation. De Jongh and colleagues (1994) found that catastrophizing and lack of cognitive control are important moderators of dental care-related anxiety. Moreover, research suggests that patient perceptions of uncontrollability, unpredictability, dangerousness, and disgustingness predict dental care-related fear and anxiety better than previous negative dental experiences (Armfield, 2010). Still, there are additional theories postulated for the development of dental care-related fear and anxiety. 
There may be temperamental or personality characteristics that predispose an individual to elevated dental care-related fear and anxiety. Perhaps there are relatively stable personality traits that affect the likelihood of an individual developing anxiety related to dental treatment. For instance, trait anxiety has been shown to be associated with adolescent-onset dental carerelated anxiety (Locker et al., 1999a). Also, in a longitudinal study aimed to examine dental care-related anxiety trajectories, Thomson, Broadbent, Locker, and Poulton (2009) found that some trajectories were highly associated with personality traits such as emotionality, self-control, and social closeness. Recent research also suggests that the personality trait of neuroticism is strongly correlated with dental care-related anxiety; however, this conclusion is qualified by the finding that the two attributes do not share identical etiologies (Vassend et al., 2011). Though personality characteristics may be important moderators of dental care-related anxiety, they clearly are not a complete explanation for the etiology of the phenomenon.

A fourth hypothesis presented to explain the etiology of dental care-related anxiety is that the phenomenon is, at least in part, a result of fear of pain or heightened pain sensitivity. McNeil and Berryman (1989) suggested that the fear of pain associated with dental treatment is an important component of dental care-related anxiety. For example, fear of possible pain may be enough to produce an anxious response to the dental treatment situation or treatment avoidance, even if extreme dental treatment-related pain never has been experienced. There is ample literature suggesting that pain is more likely to be reported by individuals who are anxious about dental treatment, and that dentally anxious patients recall more pain than is actually experienced during treatment (Kent, 1985; Maggirias \& Locker, 2002; McNeil et al., 2011). The interplay of fear of pain, pain sensitivity, and anxiety is important in understanding the complex etiology of dental care-related fear and anxiety. 
A final hypothesis related to the etiology of dental care-related fear and anxiety involves social learning. This hypothesis explains why many people are fearful of the dental situation without ever having encountered a particularly painful or negative experience (Milgrom et al., 2009). Dental fear may be communicated via observational learning, whereby a patient develops a fear of the dental situation from witnessing emotional arousal in or hearing stories from parents, friends, others, or the mass media (Milgrom et al., 2009). Children seem to be particularly vulnerable to the development of vicarious dental care-related fear, likely learning to be fearful from parents or siblings (Melamed \& Williamson, 1991).

\section{Patient Beliefs about Dentists and Dental Treatment}

The beliefs one has about dental treatment, in general, and their provider, in particular, are worth considering when discussing dental care-related fear and anxiety. These beliefs often involve attitudes of trust/distrust, judgments about dentist-patient communication, and desire for control (Abrahamsson, Ohrn, \& Hakeberg, 2009). An individual's dental treatment-related beliefs have been suggested to be important for understanding the specific etiology of one's dental care-related fear or anxiety (Milgrom et al., 2009). They may impact how a patient perceives interactions with their dentist, or, more broadly, dental care. Not surprisingly, Doerr, Lang, Nyquist, and Ronis (1998) have found that negative beliefs about dental treatment and unfavorable attitudes toward dentists are positively associated with dental care-related anxiety. These cognitions, then, are important to assess when working to understand dental care-related fear and anxiety.

\section{Classification of Dentally Fearful/Anxious Patients}

Clearly, there are numerous mechanisms by which dental care-related fear and anxiety may develop. As described, there also are a number of means by which that fear or anxiety may 
be maintained or perpetuated. Dental care-related fear and anxiety, then, is a highly individualized experience, unique for each patient. Just as the etiology of that fear or anxiety is idiographic, the manifestation or expression of the fear or anxiety is specific to the individual.

Weiner and Sheehan (1990) attempted to classify dentally anxious individuals as having one of two types of dental care-related anxiety: exogenous or endogenous. Exogenous dental care-related anxiety is the result of conditioned fear or learning history, while endogenous dental care-related anxiety is a product of some other mood or anxiety disorder. Still, this bipolar classification may be too simple of a conceptualization of the different types of dental fear that exist in the population.

Milgrom, Weinstein, Kleinknecht, and Getz (1985) devised a more sophisticated classification system, the Seattle System, to distinguish between sub-types of dental care-related anxiety. This system places anxious patients into one of four types based on a description of their fear: (a) conditioned fear of dental treatment; (b) fear of physiological arousal during dental treatment (e.g., fainting, racing heart, panic); (c) generalized anxiety and/or multiple phobias; or (d) distrust of dentists. Studies on anxious and fearful dental patients have been generally supportive of this diagnostic system; most individuals with dental care-related fear or anxiety can be categorized as one of the four types under the Seattle system (Locker, Liddell, \& Shapiro, 1999; Moore, Brodsgaard, \& Birn, 1991; Roy-Byrne, Milgrom, Khoon-Mei, Weinstein, \& Katon, 1994). The ability to classify dentally anxious individuals into one of four distinct groups suggests that dental care-related fear and anxiety is a complex phenomenon that presents itself with a fair amount of heterogeneity. 


\section{Prevalence of Dental Care-Related Fear and Anxiety and Impact on Treatment Seeking}

Though the causes and development of fear and anxiety related to dental treatment are not completely understood for all individuals, it is clear that it is a rather prevalent phenomenon. A meta-analysis by Smith and Heaton (2003) found that between 10 and 20 percent of Americans report a high level of dental care-related anxiety. The same researchers concluded that the prevalence of dental care-related anxiety has remained relatively stable over the last five decades (Smith \& Heaton, 2003). Considering the fact that there have been marked improvements in the quality and comfort associated with dental treatment delivery, the stability in prevalence of dental care-related anxiety is interesting. In a Dutch sample, dental care-related fear was the fourth most commonly reported fear, after snakes, heights, and physical injuries (Oosterink, de Jongh, \& Hoogstraten, 2009). In that same sample, dental phobia was the third most prevalent specific phobia, with acrophobia and arachnophobia ranking first and second, respectively (Oosterink et al., 2009).

The prevalence of dental care-related fear and anxiety makes it an important topic to be explored by researchers in dentistry, psychology, and public health since the phenomenon impacts treatment-seeking behavior. In a sample of university dental clinic patients, Moore and colleagues (1996) found that those with high levels of dental care-related anxiety were more likely to avoid dental treatment than were those with lower levels of dental care-related anxiety. In an urban sample of 787 participants, Doerr and colleagues (1998) found that individuals who do not receive a dental check-up at least once per year were more likely to be highly anxious about dental care than individuals who visit the dentist more frequently. Even after controlling for sociodemographic factors, treatment-seeking behavior is impacted by dental care-related 
anxiety; fear of dental pain has been positively associated with both avoiding the scheduling of a dental appointment and with utilizing dental care services (Meng, Heft, Bradley, \& Lang, 2007).

\section{Implications for Psychological and Physical Health}

The avoidance of treatment resulting from dental care-related fear and anxiety has welldocumented and far-reaching implications for psychosocial health. For instance, there are a number of negative psychosocial outcomes associated with dental care-related fear and anxiety. Doerr and colleagues (1998) determined that fear and anxiety related to dental care were positively correlated with dissatisfaction with one's mouth. This dissatisfaction may lead to a person avoiding smiling or talking in social situations for fear of embarrassment, thus negatively impacting quality of life. Further research by Crofts-Barnes, Brough, Beddis, and Girdler (2010) supported this finding - high dental anxiety scores were associated with lower scores on measures of quality of life. Lastly, it has been shown that patients reporting high levels of dental care-related fear are significantly more likely to report lower self-esteem and morale than patients who are less dentally anxious (Locker, 2003). Thus, fear and anxiety related to dental treatment are important correlates of psychological well-being.

Also important are the implications of avoidance of dental treatment on oral health. Low levels of dental care-related fear and anxiety have been associated with positive attitudes toward the dentist and better preventive behaviors such as regular brushing and flossing (Riley, Gilbert, \& Heft, 2006). Moreover, these positive attitudes have been shown to be correlated with reduced incidence of dental disease and increased compliance with dental treatment regimens (Levin \& Shenkman, 2004; Ojima et al., 2005). Schuller, Willumsen, and Holst (2003) found that patients with high levels of dental fear had a greater number of decayed and missing teeth, and a lower 
number of filled and functional teeth, than patients with less dental fear. Research suggests, then, that fear of dental care is strongly related to avoidance of treatment for oral disease.

Oral health problems that persist due to the avoidance of dental treatment have implications for overall health. Untreated oral disease may exacerbate cardiovascular disease and diabetes, among other systemic health concerns (Williams et al., 2008). A bidirectional association between periodontal disease and systemic disease has been suggested, with oral inflammation as the visible link between the two (Haumschild \& Haumschild, 2009). Systemic health problems may manifest in oral disease, just as oral disease may aggravate or intensify systemic health problems. Further, untreated oral disease may negatively impact the health of an unborn child, as it has been linked to preterm delivery and low birth weight (Gaffield, ColleyGilbert, Malvitz, \& Romaguera, 2001; Offenbacher et al., 1996). Good oral health has widereaching repercussions, as it is an important component of general health. Clearly, barriers to achieving and/or maintaining good oral health, and thus overall health, are worth considering.

Research addressing the complex phenomenon of dental care-related fear and anxiety and its implications for treatment-seeking behavior is important and has the potential to be quite impactful. The long-term goal of the proposed project was to improve our understanding of the psychosocial barriers to oral health care. Understanding the interplay of dental beliefs, dentalrelated fears, and fear of pain, as well as the effects of dental-related fear and anxiety on dental treatment-seeking behavior is critical for clinicians and researchers addressing the oral health care crisis. The project intended to yield a more thorough conceptualization of dental fear and anxiety, and an understanding of how dental-related fear and anxiety influence treatment-seeking behavior in dental patients over the long term. 


\section{Statement of the Problem}

Previous research has demonstrated that dental care-related fear and anxiety is a constellation of physiological, cognitive, and emotional experiences (e.g., de Jongh et al., 1994; Johnsen et al., 2003). Moreover, it is a complex phenomenon that may result from any of a number of mechanisms (Locker et al., 1999a; Milgrom et al., 2009; Vassend et al., 2011). At a practical level, research suggests that dental care-related fear and anxiety has implications for symptomatic treatment-seeking behavior (Armfield et al., 2007). There is a limited literature, however, addressing how specific, known correlates of dental care-related fear and anxiety are related, and how they implicate frequency and type of dental clinic visits, in particular.

Fear of pain and beliefs about dentists and dental treatment independently have been shown to be correlates of dental care-related fear and anxiety (McNeil \& Berryman, 1989; Riley et al., 2006). A review of the literature, however, suggests that the association between these constructs, fear of pain and dental beliefs, has not been well-defined in relation to their association with dental-related fears. Establishing these associations is a critical step in understanding the complex etiology of dental care-related fear and anxiety and will afford a more thorough understanding of the prevalent and important problem.

In considering the implication of dental care-related fear and anxiety on the treatmentseeking behaviors of dental patients, one might assume that the former is intricately connected to the latter. As mentioned earlier, literature suggests that high dental care-related anxiety is associated with symptomatic treatment-seeking patterns. Research has not yet addressed how fear of pain and dental beliefs, in relation to dental care-related fear and anxiety, may impact this type of treatment-seeking behavior. Understanding how the components of dental care-related fear and anxiety affect symptomatic treatment seeking is of clinical significance and utility. This 
understanding could provide researchers, clinicians, and public health officials with information that, in the long-term and with additional work, may have the ability to improve utilization of care. Thus, addressing the aims of better conceptualizing the etiology of dental care-related fear and anxiety and establishing how associated variables influence patient's care-seeking behaviors is important.

\section{Hypotheses}

Dental care-related fear and anxiety is complex and impacts emergency dental treatmentseeking behavior. Drawing on previous research (Levin \& Shenkman, 2004; McNeil \& Berryman, 1989; Meng et al., 2007; Riley et al., 2006), it was hypothesized that fear of pain and dental beliefs would be positively correlated with dental care-related fears in an Appalachian population. It also was expected that higher dental care-related fear and anxiety, and associated fear of pain and dental beliefs, would be predictive of number of visits to an emergency dental clinic (i.e., symptomatic visits) over a 10-year period. Additionally, it was anticipated that those participants who were highly fearful of the dentist would have, on average, a greater number of invasive emergency dental procedures (e.g., extractions) over the 10-year period than their less fearful counterparts. Likewise, it was anticipated that those who were highly fearful of the dentist would have, on average, a lower number of preventative or minor (i.e., restorative), dental procedures completed over the 10-year period than those who were less fearful.

\section{Method}

\section{Design}

Between April, 2001 and July, 2001, patients presenting to the Emergency Clinic (now the Urgent Dental Care Clinic) at the West Virginia University School of Dentistry were asked to complete a number of self-report measures (described below) to assess dental care-related fear 
and anxiety. This study, utilizing a retrospective cohort design, followed up on the emergency dental treatment-seeking behavior of these patients by way of comprehensive chart review. Frequency of clinic visits, types of dental procedures performed, and resulting complications over the past decade were abstracted from patient charts for each participant. Treatment-seeking behaviors were compared across patients of varying levels of dental care-related fear and anxiety previously assessed at the clinic visit in 2001 .

\section{Participants}

Participants were adult (age $\geq 18$ years at the time of study visit in 2001) patients who reported to the West Virginia University School of Dentistry's clinic for emergency dental treatment. At the time of their visit, they completed a number of self-report instruments related to dental care-related fear and anxiety, in addition to a short demographic questionnaire. They also agreed to future review of their dental charts for the purposes of research. All participants provided informed consent according to the West Virginia University Institutional Review Board's standard protocol.

Initially, dental fear and anxiety was assessed for 592 (313 female) patients. For the current project, chart review was completed for a randomly selected subset of 80 (40 female) of these individuals for whom dental charts were available, using a random number generator to determine the subset (Haahr, 2011). GPOWER 3, created by Faul, Erdfelder, Lang, and Buchner (2007), was utilized to determine the sample size of 80 participants, given moderate effect size $\left(\omega^{2}=0.25\right)$ and a desired power of $\varphi=.80$. A record of the number of selected individuals with no available dental chart was kept; these cases are reported below, but are not included in the study sample so as to maintain statistical power. 
Participants were sampled randomly but equally, according to gender and Dental Fear Survey (DFS; described below) score, as gender differences in level of dental care-related fear are well-evidenced in the literature (e.g., Craske, 2003). Consistent with previous work in the area of fear (e.g., McNeil, Vrana, Melamed, Cuthbert, \& Lang, 1993), participants with DFS scores in the top $6^{\text {th }}$ percentile and participants with DFS scores in the bottom $60^{\text {th }}$ percentile were randomly selected for inclusion in the study sample. This selection strategy was utilized in order to capture those participants with a significant and potentially impairing problem with dental care-related fear and anxiety and to compare them to a more "general" group of individuals for whom dental care-related fear and anxiety is not likely distressing enough to interrupt dental treatment-seeking but for whom there may be some level of dental care-related fear. In the end, there were 20 participants each in four "groups" of the study sample: females reporting high levels of dental care-related fear, males reporting high levels of dental care-related fear, females reporting low levels of dental care-related fear, and males reporting low levels of dental care-related fear.

Generally speaking, participants of the project were residents of rural West Virginia and Pennsylvania and represent the ethnic and racial make-up of the Appalachian area. For this study, $91.3 \%$ of the sample reported their race/ethnicity as "white/Caucasian," 5\% reported "black / African American," 2.5\% reported "Native American, and 1.3\% reported "Asian." The average age of participants included in the sample was 35.9 years $(S D=13.8$; range 19-86) and the average years of education completed by participants was $12.4(S D=2.5$; range $7-17)$.

\section{Self-Report Measures}

Demographic and general dental information questionnaire. The demographic form used for this project was a 20-item, self-report questionnaire (see Appendix A). It covered 
general demographic information, querying the respondent about physical access to dental care (i.e., method/reliability of transportation), and asked about dental history and present dental pain. Additionally, it included items related to gagging; however, these items were not be utilized for the current study.

Dental Fear Survey. The Dental Fear Survey (DFS) is a 20-item, self-report measure of anxious reactions to dental situations (Kleinknecht, Klepac, \& Alexander, 1973; see Appendix B). The instrument assesses behavioral and physiological responses to dental situations (i.e., fear of dental work leading to cancellation of an appointment, perspiration or increased heart rate during dental treatment) as well severity of anxious response to various specific situations (i.e., being seated in the dental chair, seeing the anesthetic needle, hearing the drill). Respondents are asked to rate, on a 5-point Likert scale, how much each behavioral or physiological response occurs in the dental setting or how much anxiety they experience as a result of specific instances in the dental office. The total score ranges from 20-100, with higher scores indicating more significant anxiety responses and thus greater dental care-related fear. The DFS contains three factor-analytically derived subscales: one related to patterns of dental avoidance and anticipatory anxiety, another regarding fear of specific dental stimuli or procedures, and one related to physiological arousal associated with dental treatment (Kleinknecht et al., 1973).

The DFS is a useful measure because it requires a relatively short amount of time to administer, has items that allow for a specific understanding of an individual's fear response, is widely utilized in behavioral dentistry research, and has well-evidenced reliability and validity. The authors have found stability in factors and scores across time, in clinical and non-clinical samples (Kleinknecht et al., 1973). This internal consistency and test-retest reliability has been observed in subsequent analysis (Kleinknecht, Thorndike, McGlynn, \& Harkavy, 1984; 
McGlynn, McNeil, Gallagher, \& Vrana, 1987). Studies by Smith and Moore (1994) and Wilson and Sinisko (1997) utilized the DFS and found predictive, convergent, and discriminant validity. The DFS, then, is a good measure of anxious and fearful reactions to dental situations.

Items on the DFS likely tap both dental care-related fear and dental care-related anxiety, constructs earlier described as separate. This measure, and other current self-report methods for the assessment of dental fear, do not allow for a distinction between fear and anxiety. For this reason, DFS scores will be used to indicate dental care-related fear and anxiety generally.

Fear of Pain Questionnaire. The Fear of Pain Questionnaire-III (FPQ-III) is a 30-item, self-report measure of pain-related fear (McNeil \& Rainwater, 1998; see Appendix C). The instrument consists of three subscales: Severe Pain, Minor Pain, and Medical Pain. Respondents are asked to rate, on a 5-point Likert scale, how fearful they are of experiencing the pain associated with each of a number of painful experiences (e.g., getting a paper cut, breaking your leg, having a tooth pulled). Subscale scores range from 10-50 and the total score ranges from 30-150; higher scores indicate greater fear.

The FPQ-III has the following strengths: relatively short administration time, assessment of fears related to a broad range of painful situations, established norms for clinical (i.e., chronic pain patients, general medical outpatients) and nonclinical populations, and well-evidenced reliability and validity. In the standardization samples, internal consistency was good, Cronbach's $\alpha=.92$, as was test-retest reliability, $r=.74$ (McNeil \& Rainwater, 1998). More recent studies by Osman, Breitenstein, Barrios, Gutierrez, and Kopper (2002) and Roelofs, Peters, Deutz, Spijker, and Vlaeyen (2005) found additional support for the three-factor solution of the FPQ-III and further evidence of reliability, as well as predictive, convergent, and discriminant validity. The FPQ-III, then, is a good measure of pain-related fear. For its strong 
psychometric properties and utility, and the demonstrated association between fear of pain and dental care-related fear and anxiety (McNeil \& Berryman, 1989), this instrument is of value for the proposed study.

For the purposes of this study, the Short Form of the FPQ-III (SF-FPQ; McNeil \& Rainwater, 1998) was utilized. This was done in order to reduce questionnaire completion time for participants. The SF-FPQ contains 9 items, 3 from each of the subscales of the original FPQIII. Total SF-FPQ score ranges from 9-45.

Getz Dental Beliefs Scale. The Revised Getz Dental Beliefs Survey (DBS) is a 28-item self-report measure of feelings and reactions to dental work and dentistry in general in three areas: Professionalism, Communication, and Lack of Control (see Appendix D). Respondents rate the frequency of situations or feelings on a five-point Likert-type scale from never to nearly always. Examples of items include "I believe dentists say things to withhold information from me" and "I'm concerned that dentists might not be skilled enough to deal with my fears or dental problems." Total score ranges from 28-140, with higher scores indicating a more negative overall view of dentists and dental treatment.

Administration time for the DBS is relatively short, the instrument is widely used, and there is good evidence of reliability and validity. In a sample of dentally fearful adults, a Cronbach's alpha of 0.95 was observed, indicating excellent internal consistency (Kvale, Milgrom, Getz, Weinstein, \& Johnsen, 2004). Test-retest reliability over a two- to three-week period was found to be good by Coolidge et al. (2005), $r=0.88$. Convergent and discriminant validity was found to be good for all subscales of the measure when compared to other measures of desired and predicted control (Coolidge, Heima, Coldwell, Weinstein, \& Milgrom, 2005). These findings were confirmed by Abrahamson and colleagues (2009) in a recent study of 
regular dental patients living in Sweden. For its ease of use and well-evidenced reliability and validity, the DBS is a good measure of feelings and reactions to dentistry for the proposed study.

\section{Chart Review}

Dental records were made available through the West Virginia University School of Dentistry. For each randomly chosen participant for whom a dental chart existed (80 of 89 requested), a standardized dental chart abstraction form was completed in order to organize all chart entries over the past ten years (see Appendix E). A summary form also was completed in order to organize information gathered for data entry (see Appendix F). Number of visits over the 10-year period (May 1, 2001 - May 1, 2011), procedures performed at each visit, and patient's self-reported pain ratings at each visit were recorded. This chart review process provided a comprehensive and standardized measure of dental treatment-seeking behavior.

Access to dental records was provided by School of Dentistry faculty associated with the project and chart review was conducted by the investigator and an undergraduate research assistant, under the supervision of collaborators at the School of Dentistry. Chart abstraction reliability was assessed via periodic abstraction form comparison for select cases across the data collection window, and data collectors were blind to which cases would be reviewed for reliability checking. Reliability was excellent across the data collection window; there were no discrepancies in recorded outcome variables. Prior to data collection all members of the chart review team were trained on The Health Insurance Portability and Accountability Act of 1996 (HIPAA) Privacy and Security Rules and had current ethics training and Collaborative Institutional Training Initiative (CITI) program certification for work with human subjects.

An effort was made to record the number of teeth present in each patient's mouth as of their initial study visit, and at each subsequent visit to the emergency clinic. Those data were 
made available for some participants, but not others, in the form of panogram radiographs. Number of extant teeth were recorded, with the associated date, at every point over the 10 -year period for which those data were available. The goal in collecting such data was to allow for some control of this potential predictor of future number of dental visits; however, there were only a 23 (of 80) cases for which panogram radiographs were available, and of those cases most available radiographs were obtained late in the decade for which charts were reviewed. Therefore, this variable could not be included as a control in data analyses.

Considering extractions, specifically, it is important to note that the West Virginia University School of Dentistry has in place policies which generally limit the number of teeth that can be extracted during a single appointment. It is not known whether and how these policies might have changed during the 10 -year period covered by way of chart review. In any case, time between dental visits was recorded as part of the chart review process in order to determine whether multiple visits occurring very proximally in time were the result of policies which might require a patient to, for instance, return the next day to "continue work from the day before."

\section{Statistical Analyses}

Statistical analyses were performed using PASW Statistics 18.0.3 (IBM SPSS, Chicago, IL). Effect size calculations (i.e., Cohen's $d$ ) for $t$-tests were made using Effect Size Calculators (Becker, 1999). Conventionally, a Cohen's $d$ value of .2 indicates a small effect, and values of .5 and .8 indicate medium and large effects, respectively (Cohen, 1988).

\section{Results}

Univariate outliers were observed in three cases each for two outcome variables: number of extractions over ten years and total number of visits to the dental clinic over ten years. These 
outliers were detected by considering standardized scores (i.e., $z$-scores) for the variables in question. Consistent with what is recommended in the literature (Tabachnick \& Fidell, 2007), cases for which a particular variable's standardized score was greater than $3.29(p<.001$, twotailed test) were considered to be outliers. In order to reduce their impact on analyses while maintaining the case in the dataset, these univariate outliers were recoded to a value one unit larger than the next most extreme score in the distribution, as recommended by Tabachnick and Fidell (2007, p. 77).

Analyses were completed after the outliers were addressed; for the study sample, there were no missing data for study variables. Descriptive statistics (e.g., means and standard deviations) for relevant dependent and independent variables, across the entire study sample, are reported in Table 1. Percentages of participants receiving the types of dental treatment in question are reported in Table 2. Considering the study sample, 52 of the 80 participants (65\%) returned to the university dental clinic at least once over the ten-year study period following their initial emergency visit.

Complete dental charts were not available for nine of the 89 requested charts. These cases were not included in the study sample and remained part of the overall sample. Demographically, the study sample and the overall sample were very similar. There was no significant difference in age between the study sample $(M=35.9$ years, $S D=13.8)$ and the overall sample $(M=37.2$ years, $\mathrm{SD}=15.3), t(590)=.70, p=.49$, Cohen's $d=.06$. There also was no significant difference in number of years of education completed between the study sample $(M=12.4$ years, $S D=2.5)$ and the overall sample $(M=12.6$ years, $\mathrm{SD}=2.5), t(590)=$ $.82, p=.41$, Cohen's $d=.07$. 
Bivariate correlational analysis was used to determine the relation between dental carerelated fear, fear of pain, and beliefs about the dentist and dental situation. As expected, dental care-related fear was positively associated with fear of pain, $r(78)=.54, p<.001$, and negative dental beliefs, $r(78)=.66, p<.001$, in this emergency treatment-seeking, Appalachian sample. Additionally, fear of pain and negative dental beliefs were positively and significantly correlated, $r(78)=.53, p<.001$

In order to examine the predictive association between these constructs and emergency dental treatment-seeking behavior, multiple linear regression analysis was utilized. An additive hierarchical regression was conducted, with DFS total score, SF-FPQ total score, and DBS total score as the independent variables and number of dental clinic visits as the dependent variable, controlling for patient gender, age, and years of education. Results of that regression analysis are presented in Table 3. In this model, age was the only significant predictor of number of visits to the dental clinic, $\beta=.25, p=.045$. Age also was associated with DFS total score, $r(78)=-.22, p$ $=.047$, and with DBS total score, $r(78)=-.28, p=.01$.

A second additive hierarchical regression was conducted, with DFS total score, SF-FPQ total score, and DBS total score as the independent variables and number of extractions as the dependent variable, controlling for patient gender, age, and years of education. Since, for this population, extractions typically represent an emergency visit, this dependent variable was determined to be the appropriate variable to serve as a proxy for symptomatic treatment-seeking behavior. Results of this second regression analysis are presented in Table 4. No variables inserted in this model significantly predicted number of extractions performed over the 10-year period. 
As discussed earlier, fear of pain is an important component of dental care-related fear, suggesting, theoretically, that dental care-related fear may mediate an association between fear of pain and dental treatment-seeking patterns. As such, mediational analysis was conducted on the relation between SF-FPQ score and number of dental clinic visits, with DFS total score as a mediator. Using the Baron and Kenny (1986) approach, regressions were conducted to assess the relations between SF-FPQ score and number of dental clinic visits $\left(\beta=.08, p=.45, R^{2}=\right.$ $.07)$, SF-FPQ score and DFS score $\left(\beta=.54, p<.001, R^{2}=.35\right)$, and DFS score and number of dental clinic visits $\left(\beta=.07, p=.57, R^{2}=.07\right)$, controlling for gender, age, and number of years of education. Had all three of these relations been significant, a fourth multiple regression, divided into two steps, would have been conducted to determine whether DFS score mediated the relation between SF-FPQ score and number of dental clinic visits, and significance would have been tested using a Sobel test.

A second mediational analysis was conducted on the relation between SF-FPQ score and number of extractions performed, with DFS total score as a mediator. Using the Baron and Kenny (1986) approach, regressions were conducted to assess the relations between SF-FPQ score and number of extractions $\left(\beta=-.15, p=.18, R^{2}=.08\right)$, SF-FPQ score and DFS score $(\beta=$ $\left..54, p<.001, R^{2}=.35\right)$, and DFS score and number of extractions $\left(\beta=-.05, p=.69, R^{2}=.06\right)$, controlling for gender, age, and number of years of education. Similar to the first meditational analysis, had all three of these relations been significant, a fourth multiple regression, divided into two steps, would have been conducted to determine whether DFS score mediated the relation between SF-FPQ score and number of extractions, and significance would have been tested using a Sobel test. 
Considering two groups of participants, those with high levels of dental care-related fear and anxiety and those with low levels of dental care-related fear and anxiety, there were no significant differences in the number of invasive dental procedures, such as extractions. There also were no significant differences in the number of preventative/minor dental procedures between the groups, as presented in Table 5.

\section{Exploratory Analyses}

Exploratory analyses were conducted in order to determine whether there were differences between those patients who presented to the clinic for asymptomatic treatment at least once during the 10-year study window and those who did not. Patients who received at least one cleaning over the 10 -year period reported less negative beliefs about dentists (DBS $M=$ 33.7, $S D=4.0)$ than did those who received no cleanings (DBS $M=61.1, S D=28.8), t(78)=$ 2.32, $p=.02$, Cohen's $d=0.53$. Table 6 describes those patients who sought dental treatment asymptomatically over the 10-year study window, compared to those who presented to the clinic only symptomatically.

To explore potential group differences in demographic and psychosocial variables between patients receiving different types of dental treatment (e.g., restorative procedures versus extractions), a series of $t$-tests were completed. Results from these analyses are presented in Tables 7 and 8. Notably, those who underwent at least one restorative procedure had completed, on average, a greater number of years of education $(M=13.4, S D=1.9)$ than those who had no restorative treatment over the 10-year period $(M=12.1, S D=2.6), t(78)=2.06, p=.04$, Cohen's $d=0.47$. On the contrary, those who received at least one extraction had completed, on average, fewer years of education $(M=12.0, S D=2.5)$ than those participants who had no teeth extracted over the 10-year period $(M=13.4, S D=2.2), t(78)=2.24, p=.03$, Cohen's $d=0.51$. 


\section{Discussion}

Few studies have addressed emergency treatment-seeking dental patients, particularly with regard to important psychosocial barriers to treatment utilization (e.g., fears or anxiety about the dentist or dental situation). The current study's finding that dental care-related fear, fear of pain, and negative beliefs about the dentist and dental treatment are all quite related in a population of symptomatic treatment-seeking patients is consistent with the same finding as observed in other populations. These relations are, of course, not surprising. Fear of pain, as a construct, for example, has been shown to be an important component of dental care-related fear (McNeil \& Berryman, 1989), and negative beliefs about dentists and dental treatment likely maintain and/or arise from a general fear of dental treatment. Observing these associations in an Appalachian, symptomatic treatment-seeking population suggests that these patients are similar to dental patients in other contexts, at least with regard to these variables, and that those who are fearful may benefit from psychosocial or other interventions aimed at reducing barriers to treatment utilization.

Quite unexpected is the finding that neither dental care-related fear, fear of pain, nor negative beliefs about dentistry predicted number of School of Dentistry dental clinic visits, generally, or number of emergency procedures (i.e., extractions), specifically. Results of hierarchical regression analyses did not support one of the main hypotheses of this study; for this particular emergency dental treatment-seeking population, the common psychosocial barriers to treatment utilization in question were not significant predictors of symptomatic treatmentseeking. This raises the question: What, then, best predicts emergency dental treatment-seeking behavior? While the current study cannot yield a definitive conclusion, one might hypothesize that factors such as income and/or availability of dental insurance, oral health values, health 
literacy, geographical limitations, and/or experience of pain would play important roles. Answering this question certainly is a possible future direction for research in the area of emergency dental care.

Regression analysis indicates that age is a predictor of number of visits to the dental clinic over a 10-year period. This finding might be explained quite simply; perhaps there are age-related declines in oral health status that necessitate more frequent attention from a dental professional. For example, as one ages, they may be more likely to experience dental caries or other oral disease and may, therefore, require more frequent symptomatic dental visits. Older adults also may require certain dental treatments that are associated with a greater number of required appointments. There also may be cohort differences based on historical differences in accessibility and type of "standard" dental care. Given the nature of the clinic used for data collection in this study, another possible explanation for this finding is that older adults in this Appalachian sample are less likely to have disposable income or adequate dental insurance coverage to seek treatment from dentists in private practice. If this is the case, these patients may be more likely visit the West Virginia University School of Dentistry emergency clinic, as services historically have been provided at little or no cost to patients.

That greater age predicts an increased number of visits to the dental clinic over a 10-year period might be at least partially explained by the observed negative correlations between age and dental care-related fear and negative beliefs about dentistry. Since DFS and DBS scores were not predictive of number of visits to the clinic, however, other phenomena might be operating. Older adults may generally be more receptive than younger adults to dental treatment, or they may place a greater priority on oral health care or addressing orofacial pain. Lastly, older adults may have had, over their longer life, the opportunity to learn and practice coping strategies 
to deal with barriers to utilization such as dental care-related fear and anxiety. If so, these older adults, even if they experience dental care-related fear or anxiety, would be less likely to avoid the dental clinic during times of need. Certainly, age-related differences in barriers to dental treatment access and actual utilization of care would be worth studying in future projects. This work will become particularly relevant as the average age of the United States of America increases over the next few decades.

Given that fear of pain is a critical component of dental care-related fear (McNeil \& Berryman, 1989), and that dental care-related fear has been associated with avoidance of dental treatment in many previous studies (e.g., Doerr et al., 1998; Meng et al., 2007), it was hypothesized that dental care-related fear might mediate the relation between fear of pain and number of symptomatic visits to the dental clinic. Surprisingly, this hypothesis was not supported. In fact, as mentioned earlier, dental care-related fear and fear of pain were not related to number of School of Dentistry clinic visits or number of emergency extractions, likely because other factors are predictive of visits to this type of clinic.

It is important to remember that symptomatic treatment-seeking patients were the sole focus of this study, and that such a population is both diverse and unique. While it certainly is crucial to improve our understanding of this patient population if dental care utilization and oral/systemic health outcomes are to be improved, it must be acknowledged that this group is distinct from other groups of dental patients studied before. Emergency treatment-seeking patients likely may be a group for whom treatment accessibility factors far outweigh treatment utilization factors in the decision to seek or avoid dental care. For instance, factors such as accessibility/reliability of transportation, proximity to a regular provider, ability to take time off of work, child care responsibilities, and/or socioeconomic status may be much more important in 
the "decision" to receive dental treatment and would, for this population, be more robust predictors of variables such as number of visits to the dental clinic.

Additionally, symptomatic treatment-seeking patients simply may not have strong opinions or feelings about dentists and dental treatment. Perhaps the result of oral health values or a history of minimal and infrequent exposure to dental offices, these patients may prioritize other behaviors over dental treatment. Symptomatic treatment-seekers, then, may not behave as do other previously studied patient groups. Future work might address oral health values and previous dental experiences in symptomatic versus asymptomatic treatment-seeking patients in order to determine whether the groups are different in such domains.

There is another possible explanation for the finding that dental care-related fear and fear of pain were not related to number of dental clinic visits or number of emergency extractions performed for this population. Perhaps, for these patients in particular, the level of pain experienced at the time they presented to the clinic (i.e., the reason for their visit to the emergency clinic) interfered with their self-report(s) of dental care-related fear, fear of pain, and/or negative beliefs about dental treatment. It may be the case that participants of this study, who completed measures assessing these constructs while waiting for the dentist during a emergency/symptomatic visit to the clinic, were experiencing enough pain to be essentially primed to more strongly consider feelings of fear, anxiety, apprehension, mistrust (e.g., Kirwilliam \& Derbyshire, 2008). That is, the constructs tapped by the instruments used in this study may have been especially salient for the participants, skewing participant responses and, thus, the results drawn from those responses. To control for this potential priming effect, a future study may consider measuring phenomena such as dental care-related fear or fear of pain 
in a neutral environment and at a neutral time prior to tracking dental treatment-seeking behavior over the long-term.

Some of the most interesting findings of this study were the result of exploratory data analysis. Not surprisingly, those who reported to the dental clinic for at least one cleaning during the 10-year period had, in general, less negative beliefs about the dentist. A critical question is this: How can this information be utilized in order to improve the likelihood and frequency of asymptomatic dental treatment-seeking behavior? If beliefs about dentistry, and not dental carerelated fear/anxiety or fear of pain, are most associated with future preventative dental care for the emergency treatment-seeking population, then perhaps consideration should be given to how to design, evaluate, improve, and deliver interventions that target beliefs about the dentist and dentistry. Knowledge of the impact of patient beliefs about dentistry on future preventative care could be of particular importance and utility for improving asymptomatic treatment-seeking behavior in those patients who currently interact with the dentist only on an emergency-byemergency basis. Providing these same patients with subsequent opportunities for "well visits" (i.e., preventative care) might aid in the reduction of dental care-related fear through occasion setting and other mechanisms that play out in exposure therapy (see Bouton, 1988; HazlettStevens \& Craske, 2008).

It is interesting that a significant difference in average number of years of education completed exists between those patients who underwent no restorative procedures and those patients who had at least one restorative procedure, and that a difference, in the opposite direction, exists for those patients who had no teeth extracted and those patients who had at least one tooth extracted over the 10-year period. It could be the case that individuals who have completed fewer years of education and therefore may have fewer financial resources may, as a 
result of treatment accessibility factors (i.e., money for dental care, dental insurance), put off dental treatment until it is "too late." These individuals, then, likely would face extractions, as restorative procedures would not be possible as a result of extensive infection. It also may be the case that those with higher levels of education differ from those with lower levels of education in the value placed on oral health care and/or retaining teeth. People who have completed more years of schooling may be more interested in saving teeth that are infected with caries, perhaps as a result of sociocultural influences. These patients also may feel that they have the resources to take care of restored teeth, which would lead to a preference to retain teeth, when possible, over allowing them to be extracted.

The current study is not without a number of important limitations. First, because the study utilized only dental charts from patients of the West Virginia University School of Dentistry clinics, there is no way to know whether participants received any sort of care, symptomatic or asymptomatic, from other providers over the 10 -year period that was the focus of the chart review. That is, not all dental treatment-seeking behavior over the 10-year window for all patients can be accounted for given the available data. For example, a patient who presented to the emergency clinic in May, 2001 for an extraction, may have a regular provider who provides twice-yearly cleanings and other care, but who could not schedule time for the necessary emergency procedure in that particular instance. This patient, then, would appear to have visited a dental professional only once over the 10 -year period, when in actuality likely visited over one-dozen times. Likewise, review of these charts does not allow us to ascertain whether the participant moved out of the area and subsequently began receiving treatment, symptomatic or otherwise, at another clinic. Because of the nature of the data record, these situations simply cannot be accounted for. 
A second limitation of the current study is that chart entries were not uniform across all visits. For example, some entries noting a routine extraction were far more detailed than other entries outlining the same procedure. While this affected some of the qualitative data collected for this project, it did not impact the quantitative data that were collected and used for the analyses presented here. Still, more detailed chart entries may have provided a complete set of other variables worth considering, such as patient pain/anxiety ratings or provider evaluation of patient's demeanor.

Third, number of extant teeth at each clinic visit could not be accounted for, and therefore could not be controlled for in analysis. While every effort was made to collect this information in order to provide an additional level of statistical control, it simply was not possible.

A fourth important limitation of this study is that the demographics questionnaire lacked items related specifically to socioeconomic status. The inclusion of variables such as income, wealth, and availability of dental insurance may have allowed for better control of models aimed at predicting treatment-seeking behavior. With this information, perhaps access versus utilization factors could have been accounted for in an attempt to better address the hypotheses of the study using the variables of real interest (i.e., dental care-related fear, fear of pain, beliefs about dentistry). Due to the fact that this study design relied on the use of existing data collected over 10 years ago, obtaining this information would have been essentially impossible; however, it is important to consider a key strength of this study that is highlighted by this limitation.

As a result of the availability of 10-year-old demographic and psychosocial data, it was possible to design a longitudinal study that addressed dental treatment-seeking behaviors in a poorly studied but incredibly important population: those who present for treatment symptomatically. This study allowed a decade-long snapshot of this special population to be 
produced. The result was findings that help us to better understand the characteristics of emergency treatment-seeking dental patients, particularly those who utilize a university clinic. Symptomatic treatment-seeking patients are an important group to understand, as they may especially benefit from brief interventions that occur in the emergency dental clinic, in the context of their visit. Intervention research will be well served by the data that have been collected about this unique population.

The current project is the first known longitudinal study of symptomatic treatmentseeking dental patients. Future work in the same area likely would improve the clinical practice of dentistry and the science of behavioral dentistry. One future direction of research might include designing a prospective longitudinal study that accounts for the limitations discussed here, one that includes all dental visits over a certain period of time and controls for both access and utilization factors that may be important for predicting attendance, for instance. That same study might also include structured assessment of anxiety and mood disorders to understand how their presence may implicate treatment-seeking behavior over the long-term. Such a study certainly would be strengthened by a sample size larger than the one used in the current study in order to bolster statistical power. Small sample size may be of particular issue in this study because some of the outcome variables (e.g., number of cleanings, number of restorative procedures) are delivered at low frequencies in the emergency dental clinic. Attention to this issue would improve one of the current project's limitations: the relatively small sample size (80 participants) utilized was the minimum necessary based on a priori estimation.

Other future work in this area may draw on a sample that is recruited from the community, generally (i.e., from shopping centers, festivals, or by way of newspaper or radio advertisements), and not from the dental clinic per se. Considering that one of the key variables 
addressed in this work is fear of the dentist, and that there is an avoidance of dental clinics associated with that particular fear, it stands to reason that enrolling participants who may be fearful enough of dental treatment that they avoid it altogether would provide a better picture of the population impacted by dental care-related fear. Following these individuals over the longterm may be particularly beneficial to science and clinical practice and may provide insight that is important for the development of interventions that reduce dental care-related fear to improve treatment utilization.

With the ultimate goal of understanding factors that would allow for the improvement of dental treatment utilization, this longitudinal study addressed a group about which there exists very little knowledge: the symptomatic treatment-seeker. Understanding how the components of dental care-related fear and anxiety affect this group, in particular, might unlock mechanisms that should be targeted for behavior change in the realm of dental treatment utilization. Such interventions have significant clinical implications - if critical barriers to dental treatmentseeking behavior can be reduced, then oral health and, ultimately, systemic health can be improved. 


\section{References}

Abrahamson, K. H., Ohrn, K., \& Hakeberg, M. (2009). Dental beliefs: Factor structure of the revised dental beliefs survey in a group of regular dental patients. European Journal of Oral Sciences, 117, 720-727.

Armfield, J. (2010). Towards a better understanding of dental anxiety and fear: Cognition vs. experiences. European Journal of Oral Sciences, 118, 259-264.

Armfield, J., Stewart, J. F., \& Spencer, J. A. (2007). The vicious cycle of dental fear: Exploring the interplay between oral health, service utilization and dental fear. BMC Oral Health, 7, $1-15$.

Baron, R. M., \& Kenny, D. A. (1986). The moderator-mediator variable distinction in social psychological research: Conceptual, strategic, and statistical considerations. Journal of Personality and Social Psychology, 51, 1173-1182.

Becker, L. E. (1999). Effect Size Calculators. Retrieved from: http://www.uccs.edu/ faculty/lbecker/

Bouton, M. E. (1988). Context and ambiguity in the extinction of emotional learning: Implications for exposure therapy. Behaviour Research and Therapy, 26, 137-149.

Bouton, M. E. (2007). Learning and behavior: A contemporary synthesis. Sunderland, MA: Sinauer.

Boyle, C.A., Newton, T., Heaton, L. J., Afzali, S., \& Milgrom, P. (2010). What happens after referral for sedation? British Dental Journal, 208, E22.

Cohen, J. (1988). Statistical power analysis for the behavioral sciences $\left(2^{\text {nd }}\right.$ ed.). Oxford, UK: Lawrence Erlbaum Associates. 
Coolidge, T., Heima, M., Coldwell, S., Weinstein, P., \& Milgrom, P. (2005). Psychometric properties of the revised dental beliefs survey. Community Dentistry and Oral Epidemiology, 33, 289-297.

Craske, M. G. (2003). Origins of phobias and anxiety disorders: Why more women than men? Oxford, UK: Elsevier Ltd.

Crofts-Barnes, N., Brough, K., Beddis, A., \& Girdler, N. (2010). Anxiety and quality of life in phobic dental patients. Journal of Dental Research, 89, 302-306.

Dailey, Y. M., Crawford, A. N., Humphris, G., \& Lennon, M. A. (2001). Factors affecting dental attendance following treatment for dental anxiety in primary dental care. Journal of the Faculty of General Dental Practitioners, 8, 51-56.

Davis, E. E., Deinard, A. S., \& Maiga, E. W. H. (2010). Doctor, my tooth hurts: The costs of incomplete dental care in the emergency room. Journal of Public Health Dentistry, 70, 205-210.

de Jongh, A., Muris, P., ter Horst, G., van Zuuren, F., \& de Wit, C. (1994). Cognitive correlates of dental anxiety. Journal of Dental Research, 73, 561-566.

Dionne, R. A., Gordon, S. M., McCullagh, L. M., \& Phero, J. C. (1998). Assessing the need for anesthesia and sedation in the general population. Journal of the American Dental Association, 129, 167-173.

Doerr, P. A., Lang, W. P., Nyquist, L. V., \& Ronis, D. L. (1998). Factors associated with dental anxiety. Journal of the American Dental Association, 129, 1111-1119.

Faul, F., Erdfelder, E., Lang, A.-G., \& Buchner, A. (2007). G*Power 3: A flexible statistical power analysis program for the social, behavioral, and biomedical sciences. Behavior Research Methods, 39, 175-191. 
Fehrenbach, M. J., \& Weiner, J. (2009). Review of dental hygiene. St. Louis: Saunders Elsevier.

Gaffield, M. L., Colley-Gilbert, B. J., Malvitz, D. M., \& Romaguera, R. (2001). Oral health during pregnancy: An analysis of information collected by the pregnancy risk assessment monitoring system. Journal of the American Dental Association, 132, 1009-1016.

Haahr, M. (2011). True random number service: List randomizer. Retrieved from: http://www.random.org/lists/

Haumschild, M. S., \& Haunschild, R. J. (2009). The importance of oral health in long-term care. Journal of the American Medical Directors Association, 10, 667-671.

Hawley, G. M., Holloway, P. J., \& Davies, R. M. (1997). Dental health status associated with documented dental attendance patterns in adolescents. Community Dental Health, 14, $22-$ 24.

Hazlett-Stevens, H., \& Craske, M. G. (2008). Live (in vivo) exposure. In W. T. O’Donohue \& J. E. Fisher (Eds.), Cognitive Behavior Therapy (2nd Ed.) (pp. 309-316). Hoboken, NJ: John Wiley \& Sons, Inc.

Johnsen, B. H., Thayer, J. F., Laberg, J. C., Wormnes, B., Raadal, M., Skaret, E., ... Berg, E. (2003). Attentional and physiological characteristics of patients with dental anxiety. Anxiety Disorders, 17, 75-87.

Kent, G. (1985). Memory of dental pain. Pain, 21, 187-194.

Kirwilliam, S. S., \& Derbyshire, S. W. G. (2008). Increased bias to report heat or pain following emotional priming of pain-related fear. Pain, 137, 60-65.

Kleinknecht, R., Klepac, R., \& Alexander L. D. (1973). Origins and characteristics of fear of dentistry. Journal of Dental Research, 86, 842-848. 
Kleinknecht, R., Thorndike, R. M., McGlynn, F. D., \& Harkavy, J. (1984). Analysis of the Dental Fear Survey with cross-validation. Journal of the American Dental Association, $108,59-61$.

Kvale, G., Milgrom, P., Getz, T., Weinstein, P., \& Johnsen, T. B. (2004). Beliefs about professional ethics, dentist-patient communication, control and trust among fearful dental patients: The factor structure of the revised Dental Beliefs Survey. Acta Odontologica Scandinavica, 62, 21-29.

Levin, L., \& Shenkman, A. (2004). The relationship between dental caries status and oral health attitudes and behavior in young Israeli adults. Journal of Dental Education, 68, 11851191.

Locker, D. (2003). Psychosocial consequences of dental fear and anxiety. Community Dentistry and Oral Epidemiology, 31, 144-151.

Locker, D., Liddell, A., Dempster, L., \& Shapiro, D. (1999a). Age of onset of dental anxiety. Journal of Dental Research, 78, 790-796.

Locker, D., Liddell, A., \& Shapiro, D. (1999b). Diagnostic categories of dental anxiety: A population-based study. Behaviour Research and Therapy, 37, 25-37.

Luzzi, L., Jones, K, Spencer, A. J., \& Roberts-Thomson, K. F. (2009). Association of urgent dental care with subjective oral health indicators and psychosocial impact. Community Dental Health, 26, 77-83.

Maggirias J., \& Locker, D. (2002). Psychological factors and perceptions of pain associated with dental treatment. Community Dentistry and Oral Epidemiology, 30, 151-159.

Mason, J. (2005). Concepts in dental public health. Baltimore: Lippincott Williams \& Williams. 
McGlynn, F. D., McNeil, D. W., Gallagher, S. L., \& Vrana, S. (1987). Factor structure, stability, and internal consistency of the dental fear survey. Behavioral Assessment, 9, 57-66.

McNeil, D., \& Berryman, L. (1989). Components of dental fear in adults. Behaviour Research and Therapy 27, 233-236.

McNeil, D. W., Helfer, A. J., Weaver, B. D., Graves, R. W., Kyle, B. N., \& Davis, A. M. (2011). Memory of pain and anxiety associated with tooth extraction. Journal of Dental Research, 90, 220-224.

McNeil, D. W., \& Rainwater, A., J. (1998). Development of the Fear of Pain Questionnaire-III. Journal of Behavioral Medicine, 21, 389-410.

McNeil, D. W., Vargovich, A. M., Turk, C. L., \& Ries, B. J. (in press). Anxiety and fear. In V. Ramachandran (Ed.), Encyclopedia of human behavior (2nd ed.). San Diego: Academic Press.

McNeil, D. W., Vrana, S. R., Melamed, B. G., Cuthbert, B. N., \& Lang, P. J. (1993). Emotional imagery in simple and social phobia: Fear versus anxiety. Journal of Abnormal Psychology, 102, 212-225.

Melamed, B. G., \& Williamson, D. J. (1991). Programs for the treatment of dental disorders: Dental anxiety and tempromandibular disorders. In J. Sweet, R. Rozensky, \& S. Tovian. (Eds.), Handbook of psychology in medical settings. New York: Plenum Press.

Meng, X., Heft, M., Bradley, M., \& Lang, P. (2007). Effect of fear on dental utilization behaviors and oral health outcome. Community Dentistry and Oral Epidemiology, 35, 292-301.

Milgrom, P., Weinstein, P., \& Heaton L. J. (2009). Treating fearful dental patients: A patient management handbook (3rd ed.). Seattle, WA: Dental Behavioral Resources. 
Milgrom, P., Weinstein, P., Kleinknecht, R., \& Getz, T. (1985). Treating fearful dental patients. Reston, VA: Reston Publishing Co.

Moore, R., Brodsgaard, I., \& Birn, H. (1991). Manifestations, acquisition and diagnostic categories of dental fear in a self-referred population. Behaviour Research and Therapy, 29, 51-60.

Moore, R., Brodsgaard, I., Mao, T. K., Kwan, H.W., Shiau, Y. Y., \& Knudsen, R. (1996). Fear of injections and report of negative dentist behavior among Caucasian, American, and Taiwanese adults from dental school clinics. Community Dentistry and Oral Epidemiology, 24, 292-295.

Nathe, C. N. (2005). Dental public health and research. Upper Saddle River, NJ: Pearson Education Inc.

Offenbacher, S., Katz, V., Fertik, G., Collins, J., Boyd, D., Maynor, G., McKaig, R., \& Beck, J. (1996). Periodontal infection as a possible risk factor for preterm low birth weight. Journal of Periodontology, 67, 1103-1113.

Ojima, M., Kanagawa, H., Nishida, N., Nagata, H., Hanioka, T., \& Shizukuishi, S. (2005). Relationship between attitudes toward oral health at initial office visit and compliance with supportive periodontal treatment. Journal of Clinical Periodontology, 32, 364-368.

Oosterink, F., de Jongh, A., \& Hoogstraten, J. (2009). Prevalence of dental fear and phobia relative to other fear and phobia subtypes. European Journal of Oral Sciences, 117, 135143.

Osman, A., Breitenstein, J. L., Barrios, F. X., Gutierrez, P. M., \& Kopper, B. A. (2001). The Fear of Pain Questionnaire-III: Further reliability and validity with nonclinical samples. Journal of Behavioral Medicine, 25, 155-173. 
Riley, J. L., Gilbert, G. H., \& Heft, M. W. (2006). Dental attitudes: Proximal basis for oral health disparities in adults. Community Dentistry and Oral Epidemiology, 34, 289-298.

Roelofs, J., Peters, M. L., Deutz, J., Spijker, C., \& Vlaeyen, J. W. (2005). The fear of pain questionnaire (FPQ): Further psychometric examination in a non-clinical sample. Pain, 116, 339-346.

Roy-Byrne, P., Milgrom, P., Khoon-Mei, T., Weinstein, P., \& Katon, W. (1994).

Psychopathology and psychiatric diagnosis in subjects with dental phobia. Journal of Anxiety Disorders, 8, 19-31.

Schuller, A., Willumsen, T., \& Holst, D. (2003). Are there differences in oral health and oral health behavior between individuals with high and low dental fear? Community Dentistry and Oral Epidemiology, 31, 116-121.

Smith, T., \& Heaton, L. (2003). Fear of dental care: Are we making any progress? Journal of the American Dental Association, 134, 1101-1108.

Smith, T., \& Moore, R. A. (1995). Repression of dental anxiety. Journal of Dental Research, 74, 144.

Tabachnick, B. G., \& Fidell, L. S. (2007). Using multivariate statistics. Boston, MA: Pearson.

Thomson, W. M., Broadbent, J. M., Locker, D., \& Poulton, R. (2009). Trajectories of dental anxiety in a birth cohort. Community Dentistry and Oral Epidemiology, 37, 209-219.

Vassend, O., Roysamb, E., \& Nielsen, C. S. (2011). Dental anxiety in relation to neuroticism and pain sensitivity. A twin study. Journal of Anxiety Disorders, 25, 302-308.

Vrana, S., McNeil, D., \& McGlynn, D. (1986). A structured interview for assessing dental fear. Journal of Behavior Therapy and Experimental Psychiatry, 17, 175-178.

Weiner, A., \& Sheehan, D. (1990). Etiology of dental anxiety: Psychological trauma or CNS 
chemical imbalance? General Dentistry, 22, 39-43.

Williams, R., Barnett, A. H., Claffey, N., Davis, M., Gadsby, R., Kellett, M., Lip, G.Y., \& Thackray, S. (2008). The potential impact of periodontal disease on general health: A consensus view. Current Medical Research and Opinion, 24, 1635-1643.

Wilson, J. F., \& Sinisko, S. A. (1997). Increased self-reported dental anxiety following completion of a dental history questionnaire. Psychological Reports, 81, 59-62. 
Table 1

Participant Characteristics and Outcome Variable Descriptive Statistics for Study Sample

\begin{tabular}{|c|c|c|c|c|}
\hline & Mean & $\begin{array}{c}\text { Standard } \\
\text { Deviation }\end{array}$ & Minimum & Maximum \\
\hline Age (years) & 35.9 & 13.8 & 19 & 86 \\
\hline Years of Education & 12.4 & 2.5 & 7 & 17 \\
\hline Total SF-FPQ Score & 24.6 & 8.0 & 9 & 43 \\
\hline Total DFS Score & 55.8 & 26.8 & 20 & 100 \\
\hline Total DBS Score & 59.0 & 28.7 & 27 & 140 \\
\hline Number of Cleanings & .3 & 1.7 & 0 & 15 \\
\hline Number of Restorative Procedures & .9 & 2.5 & 0 & 14 \\
\hline Number of Extractions & 2.8 & 3.5 & 0 & 14 \\
\hline Number of Appliance Visits & .6 & 2.4 & 0 & 13 \\
\hline Number of "Other" Visits & .3 & 1.0 & 0 & 5 \\
\hline Total Number of Visits & 4.8 & 5.5 & 1 & 23 \\
\hline Number of Missed Appointments & .4 & 1.2 & 0 & 6 \\
\hline
\end{tabular}


Table 2

Percentages of Study Sample Receiving Preventative, Restorative, and Emergency Dental Procedures

$\begin{array}{cc}\text { Number Receiving No Procedure } & \begin{array}{c}\text { Number Receiving At Least } \\ \text { One Procedure }\end{array}\end{array}$

One Procedure

\begin{tabular}{lcc}
\hline Cleanings & $74(92.5 \%)$ & $6(7.5 \%)$ \\
Restorative Procedures & $61(76.3 \%)$ & $19(23.8 \%)$ \\
Extractions & $21(26.3 \%)$ & $59(73.8 \%)$ \\
Appliance Visits & $74(92.5 \%)$ & $6(7.5 \%)$ \\
"Other" Procedures & $67(83.8 \%)$ & $13(16.3 \%)$ \\
Missed Appointments & $66(82.5 \%)$ & $14(17.5 \%)$ \\
\hline
\end{tabular}


Table 3

Regression Model: Predicting Total Number of Dental Clinic Visits over a Decade

\begin{tabular}{lcccc}
\hline Predictor Variable & $\begin{array}{c}\text { Unstandardized } \\
\text { Regression } \\
\text { Coefficient (B) }\end{array}$ & Standard Error & $\begin{array}{c}\text { Standardized } \\
\text { Regression } \\
\text { Coefficient }(\beta)\end{array}$ & $\begin{array}{c}\text { Significance } \\
\text { Value }(p)\end{array}$ \\
\hline Gender & 1.29 & 1.34 & .12 & .34 \\
Age (years) & .10 & .05 & .25 & .045 \\
Years of Education & .19 & .26 & .09 & .46 \\
SF-FPQ Score & .04 & .10 & .06 & .67 \\
DFS Score & .002 & .03 & .01 & .96 \\
DBS Score & .007 & .03 & .23 & .82 \\
\hline
\end{tabular}

Note: For this model, $R^{2}=.07$, Adjusted $R^{2}=-.003$. 
Table 4

Regression Model: Predicting Extraction Procedures Performed over a Decade

\begin{tabular}{lcccc}
\hline Predictor Variable & $\begin{array}{c}\text { Unstandardized } \\
\text { Regression } \\
\text { Coefficient (B) }\end{array}$ & Standard Error & $\begin{array}{c}\text { Standardized } \\
\text { Regression } \\
\text { Coefficient }(\beta)\end{array}$ & $\begin{array}{c}\text { Significance } \\
\text { Value }(p)\end{array}$ \\
\hline Gender & -1.01 & .83 & -.15 & .23 \\
Age (years) & -.01 & .03 & -.06 & .64 \\
Years of Education & -.23 & .16 & -.17 & .15 \\
SF-FPQ Score & -.05 & .06 & -.11 & .43 \\
DFS Score & .02 & .02 & .17 & .28 \\
DBS Score & -.03 & .02 & -.25 & .13 \\
\hline
\end{tabular}

Note: For this model, $R^{2}=.11$, Adjusted $R^{2}=.03$. 
Table 5

Average Number of Cleanings, Restorative Procedures, and Extractions by Dental Care-Related Fear Group

\begin{tabular}{lccccc}
\hline & $\begin{array}{c}\text { High Fear Group } \\
M(S D)\end{array}$ & $\begin{array}{c}\text { Low Fear Group } \\
M(S D)\end{array}$ & $t(78)$ & $p$ & Cohen's $d$ \\
\hline Cleanings & $.05(.3)$ & $.5(2.4)$ & 1.28 & .21 & .29 \\
Restorative Procedures & $.5(1.2)$ & $1.4(3.3)$ & 1.51 & .14 & .34 \\
Extractions & $2.6(3.9)$ & $2.9(3.1)$ & .38 & .70 & .08 \\
& & & & & \\
\hline
\end{tabular}


Table 6

Differences in Demographic and Psychosocial Variables between Patients who Received Asymptomatic Care and Patients who did not

\begin{tabular}{lccccc}
\hline & $\begin{array}{c}\text { Received No } \\
\text { Cleaning } \\
M(S D)\end{array}$ & $\begin{array}{c}\text { Received At Least } \\
\text { One Cleaning } \\
M(S D)\end{array}$ & $t(78)$ & $p$ & Cohen's $d$ \\
\hline Age (years) & $35.2(13.4)$ & $44.2(16.5)$ & 1.54 & .13 & .35 \\
Years of Education & $12.3(2.5)$ & $13.7(1.4)$ & 1.34 & .18 & .30 \\
SF-FPQ Score & $24.9(5.8)$ & $20.0(5.8)$ & 1.46 & .15 & .33 \\
DFS Score & $57.3(26.6)$ & $37.0(23.2)$ & 1.81 & .07 & .41 \\
DBS Score & $61.1(28.8)$ & $33.7(4.0)$ & 2.32 & .02 & .53 \\
\hline
\end{tabular}


Table 7

Differences in Demographic and Psychosocial Variables between Patients who Received at least one Restorative Procedure and Patients who did not

\begin{tabular}{lccccc}
\hline & $\begin{array}{c}\text { Received No } \\
\text { Restorations } \\
M(S D)\end{array}$ & $\begin{array}{c}\text { Received At Least } \\
\text { One Restoration } \\
M(S D)\end{array}$ & $t(78)$ & $p$ & Cohen's $d$ \\
\hline Age (years) & $34.0(13.5)$ & $42.0(13.1)$ & 2.27 & .03 & .51 \\
Years of Education & $12.1(2.6)$ & $13.4(1.9)$ & 2.06 & .04 & .47 \\
SF-FPQ Score & $24.3(7.7)$ & $27.4(8.8)$ & .51 & .61 & .12 \\
DFS Score & $55.4(26.4)$ & $57.0(28.5)$ & .55 & .58 & .05 \\
DBS Score & $58.0(27.6)$ & $62.2(32.4)$ & .22 & .83 & .13 \\
\end{tabular}


Table 8

Differences in Demographic and Psychosocial Variables between Patients who Received at least one Extraction and Patients who did not

\begin{tabular}{lccccc}
\hline & $\begin{array}{c}\text { Received No } \\
\text { Extractions } \\
M(S D)\end{array}$ & $\begin{array}{c}\text { Received At Least } \\
\text { One Extraction } \\
M(S D)\end{array}$ & $t(78)$ & $p$ & Cohen's $d$ \\
\hline Age (years) & $35.1(13.6)$ & $36.2(13.9)$ & .33 & .74 & .08 \\
Years of Education & $13.4(2.2)$ & $12.0(2.5)$ & 2.24 & .03 & .51 \\
SF-FPQ Score & $27.1(8.5)$ & $23.7(7.6)$ & 1.69 & .10 & .38 \\
DFS Score & $62.1(27.8)$ & $53.5(26.2)$ & 1.27 & .21 & .29 \\
DBS Score & $67.1(33.5)$ & $56.1(26.5)$ & 1.52 & .13 & .35 \\
\hline
\end{tabular}




\section{Appendix A}

Demographic and General Dental Information Questionnaire

Name (print):

Date:

1. What is your gender?

2. What is your age?

3. What is your race/ethnicity?

4. What is your marital status?

5. Number of years of education?

6. What is your job or occupation?

7. What is your current job or occupation status?

8. How do you get to dental appointments?
Male $\quad$ Female years

White/Caucasian

Black/African American

Hispanic

Asian

Native American

Other:

Single Separated

Married Divorced

Live-in partner Widowed

(For example, High School Diploma = 12 years, College Degree $=16$ years)

Working full time

Working part time

Looking for work - unemployed

Retired

Disabled - unable to work

Have a car/truck/vehicle that I primarily or solely use

Have a car/truck/vehicle that I share with a spouse/partner

Borrow a car/truck/vehicle

Have a family member bring me

Have a friend bring me

Have a social services agency bring me Other: 
9. For the vehicle that gets you to dental appointments, how reliably does it run?

$\begin{array}{lllll}0 & 1 & 2 & 3 & 4 \\ \text { Very } & & & \text { Very } \\ \text { Unreliable } & & & \text { Reliable }\end{array}$

10. What factors make it difficult for you to schedule or attend dental appointments?

(circle or list all that apply)

hard to get away from work child care responsibilities transportation hard to arrange

Other:

11. How long since you last saw a dentist?

6 months or less

6 months - 1 year

$1-2$ years

$2-5$ years

$5-10$ years

More than 10 years

Never saw a dentist

12. When you go to the dentist, what typically gets you to go?

Regular cleaning and exam

Pain

Seeing a cavity or another problem in my mouth Other:

13. Do you presently have any dental pain?

$\begin{array}{lllll}0 & 1 & 2 & 3 & 4 \\ \text { No } & & & & \text { Severe } \\ \text { Pain } & & & & \text { Pain }\end{array}$

$\begin{array}{lllllll}\text { 14. Have you ever had problems } & 0 & 1 & 2 & 3 & 4\end{array}$ with gagging during dental visits? Never

Almost Always or Always

15. If you have EVER had problems $\quad \begin{array}{llllll}0 & 1 & 2 & 3 & 4\end{array}$ with gagging during dental visits, Very how severe have these problems Mild Very been?

16. If you have EVER had problems $\quad \begin{array}{llllll}0 & 1 & 2 & 3 & 4\end{array}$ with gagging during dental visits, Never how often has gagging interrupted the dental treatment?

Almost Always or Always

17. What triggers your gagging during dental visits? (list ALL that apply) (For example, x-rays, impressions, fingers in your mouth, instruments in your mouth) 


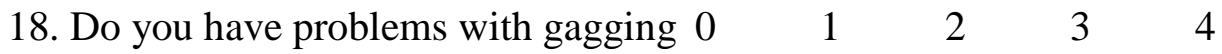

at times other than dental visits? Never

19. If you have EVER had problems with gagging at times other than Very dental visits, how severe have these Mild problems been?

0
Very
Mild

20. What triggers your gagging at these other times? (list ALL that apply) (For example, brushing your teeth, eating certain foods)
Almost

Almost Always or Always

$\begin{array}{llll}1 & 2 & 3 & 4\end{array}$

Very

Severe 


\section{Appendix B}

\section{Dental Fear Survey}

INSTRUCTIONS: The items in this questionnaire refer to various situations, feelings, and reactions related to dental work. Please rate your feeling or reaction on these items by using the following scales. Fill in the appropriate circle which most closely corresponds to your reaction.

1. Has fear of dental work ever caused you Never Once or A few

Often Nearly to put off making an appointment?

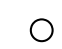

2. Has fear of dental work ever caused you to cancel or not appear for an appointment?

When having dental work done:

3. My muscles become tense...

Not At All A little Somewhat Much Very much

4. My breathing rate increases...

0
0
0

5. I perspire...

6. I feel nauseated and sick to my stomach...

7. My heart beats faster...

Following is a list of things, and situations that many people mention as being somewhat anxiety or fear producing. Please rate how much fear, anxiety, or unpleasantness each of them causes you. (If it helps, try to imagine yourself in each of these situations and describe what your common reaction is.)

8. Making an appointment for dentistry.

$\begin{array}{ccccc}\begin{array}{c}\text { Not At } \\ \text { All }\end{array} & \text { A little } & \text { Somewhat } & \text { Much } & \begin{array}{c}\text { Very } \\ \text { much }\end{array} \\ 0 & 0 & 0 & 0 & 0 \\ 0 & 0 & 0 & 0 & 0 \\ 0 & 0 & 0 & 0 & 0 \\ 0 & 0 & 0 & 0 & 0 \\ 0 & 0 & 0 & 0 & 0 \\ 0 & 0 & 0 & 0 & 0 \\ 0 & 0 & 0 & 0 & 0 \\ 0 & 0 & 0 & 0 & 0\end{array}$

9. Approaching the dentist's office.

10. Sitting in the waiting room.

11. Being seated in the dental chair.

12. The smell of the dentist's office.

13. Seeing the dentist walk in.

14. Seeing the anesthetic needle.

15. Feeling the needle injected. 
16. Seeing the drill.

17. Hearing the drill.

18. Feeling the vibrations of the drill.

19. Having your teeth cleaned.

20. All things considered, how fearful are you of having dental work done?

$\begin{array}{lllll}0 & 0 & 0 & 0 & 0 \\ 0 & 0 & 0 & 0 & 0 \\ 0 & 0 & 0 & 0 & 0 \\ 0 & 0 & 0 & 0 & 0 \\ 0 & 0 & 0 & 0 & 0\end{array}$




\section{Appendix C}

\section{Fear of Pain Questionnaire}

INSTURCTIONS: The items listed below describe painful experiences. Please look at each item and think about how FEARFUL you are of experiencing the PAIN associated with each item. If you have never experienced the PAIN of a particular item, please answer on the basis of how FEARFUL you expect you would be if you had such an experience. Fill in one circle for each item below to rate your FEAR OF PAIN in relation to each event.

$\begin{array}{ccccc}\text { Not At } & \text { A } & \text { A Fair } & \text { Very } & \text { Extreme }\end{array}$

1. Being in an automobile accident.

All

2. Biting your tongue while eating.

3. Breaking your arm.

4. Cutting your tongue licking an envelope.

5. Having a heavy object hit you in the head.

6. Breaking your leg.

7. Hitting a sensitive bone in your elbow - your "funny bone."

8. Having a blood sample drawn with a hypodermic needle.

9. Having someone slam a heavy car door on your hand.

10. Falling down a flight of concrete stairs.

11. Receiving an injection in your arm.

12. Burning your fingers with a match.

13. Breaking your neck.

14. Receiving an injection in your hip/buttocks.

15. Having a deep splinter in the sole of your foot probed and removed with tweezers.

16. Having an eye doctor remove a foreign particle stuck in your eye.

17. Receiving an injection in your mouth.

18. Being burned on your face by a lit cigarette.

19. Getting a paper-cut on your finger.

O 0

$0 \quad 0$

O $\quad 0$

O $\quad 0$

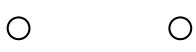

O $\quad 0$

$0 \quad 0$

$0 \quad 0$

○

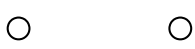

$0 \quad 0$

$0 \quad 0$

$0 \quad 0$

$0 \quad 0$

$0 \quad 0$

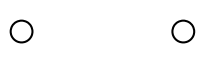

O 0

O $\quad 0$

$0 \quad 0$
Amount Much

$O$

0

O

○

○

○

○

O

○

O

O

$\mathrm{O}$

O

O

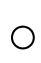

○

0

O

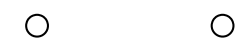

O

O

O

O

○

O

O

O

O

○

O

O

○

O

O

O

O

O

O 
20. Receiving stitches in your lip.

21. Having a foot doctor remove a wart from your foot with a sharp instrument.

22. Cutting yourself while shaving with a sharp razor.

23. Gulping a hot drink before it has cooled.

24. Getting strong soap in both your eyes while bathing or showering.

25. Having a terminal illness that causes you daily pain.

26. Having a tooth pulled.

27 . Vomiting repeatedly because of food poisoning.

28. Having sand or dust blow into your eyes.

29. Having one of your teeth drilled.

30. Having a muscle cramp.

$\begin{array}{lllll}0 & 0 & 0 & 0 & 0 \\ 0 & 0 & 0 & 0 & 0 \\ 0 & 0 & 0 & 0 & 0 \\ 0 & 0 & 0 & 0 & 0 \\ 0 & 0 & 0 & 0 & 0 \\ 0 & 0 & 0 & 0 & 0 \\ 0 & 0 & 0 & 0 & 0 \\ 0 & 0 & 0 & 0 & 0 \\ 0 & 0 & 0 & 0 & 0 \\ 0 & 0 & 0 & 0 & 0 \\ 0 & 0 & 0 & 0 & 0\end{array}$




\section{Appendix D}

\section{Dental Beliefs Scale}

The items in this questionnaire refer to various situations, feelings, and reactions related to dental work. Please rate your feelings or beliefs on these items by circling the number $(1,2,3,4$, or 5) of the category which most closely corresponds to your feelings about dentistry in general.

1. I am concerned that dentists recommend

Never work that is not really needed.

2. I believe dentists say/do things to withhold information from me.

3. I worry if the dentist is technically competent and is doing quality work.

4. I have had dentists say one thing and do another.

5. I am concerned that dentists provide all the information I need to make good decisions.

6. Dentists don't seem to care that patients sometimes need a rest.

7. I've had dentists seem reluctant to correct work unsatisfactory to me.

8. When a dentist seems in a hurry I worry that I'm not getting good care.

9. I am concerned that the dentist is not really looking out for my best interests.

10. Dentists focus too much on getting the job done and not enough on the patients comfort.

11. I'm concerned that dentists might not be skilled enough to deal with my fears or dental problems.

12. I feel dentists do not provide clear explanations.

13. I am concerned that dentists do not like to take the time to really talk to patients.

14. I feel uncomfortable asking questions.

15. Dental professionals say things to make me feel guilty about the way I care for my teeth.

16. I am concerned that dentists will not take my worries (fears) about dentistry seriously.

1

1

1

1

1

1

$\begin{array}{lcccc} & \text { Twice } & \text { Times } & & \text { Always } \\ 1 & 2 & 3 & 4 & 5\end{array}$

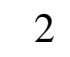

3

4

5

2

3

4

2

2

3

3

4

5

5

2

2

3

3

2

3

2

3

4

\section{5}

5

5

5

5

5

$\begin{array}{lllll}1 & 2 & 3 & 4 & 5\end{array}$

$\begin{array}{lllll}1 & 2 & 3 & 4 & 5\end{array}$

$\begin{array}{lllll}1 & 2 & 3 & 4 & 5\end{array}$

$\begin{array}{lllll}1 & 2 & 3 & 4 & 5 \\ 1 & 2 & 3 & 4 & 5 \\ 1 & 2 & 3 & 4 & 5\end{array}$


17. I am concerned that dentists will put me down (make light of my fears).

18. I am concerned that dentists do not like it when a patient makes a request.

19. I am concerned that dental personnel will embarrass me over the condition of my teeth.

20. I believe that dentists don't have enough empathy for what it is really like to be a patient.

21. When I am in the chair I don't feel like I can stop the appointment for a rest if I feel the need.

22. Dentists don't seem to notice that patients sometimes need a rest.

23. Once I am in the chair I feel helpless (that $\quad \begin{array}{llll}1 & 2 & 3 & 4\end{array}$ things are out of my control).

24. If I were to indicate that it hurts, I think 1 that the dentist would be reluctant to stop and try to correct the problem.

25. I have had dentists not believe me when I said I felt pain.

26. Dentists often seem in a hurry, so I feel rushed.

27. I am concerned that the dentist will do what he wants and not really listen to me while I'm in the chair.

28. Being overwhelmed by the amount of work needed (all the bad news) could be enough to keep me from beginning treatment. 
Appendix E

Chart Abstraction Form

Participant name:

ID:

Address:

DOB:

Date of study visit:

Pan Available: $\mathrm{Y} \quad \mathrm{N}$

Current tobacco use: $\mathrm{Y} \quad \mathrm{N}$ Previous tobacco use: $\mathrm{Y} \quad \mathrm{N}$

Amount:

Medications:

Mental health concerns:

Previous problems with/during dental care:

Visit \#

\begin{tabular}{|l|c|c|c|c|c|}
\hline Date & Stated Reason & Pain Rating & Diagnosis & \# Teeth (Pan) & $\begin{array}{c}\text { Procedure } \\
\text { (Tooth \#) }\end{array}$ \\
\hline & & & & & \\
\cline { 2 - 5 } & $\begin{array}{c}\text { Local } \\
\text { Anesthetic }\end{array}$ & $\begin{array}{c}\text { Noted } \\
\text { Anxiety }\end{array}$ & $\begin{array}{c}\text { Drugs } \\
\text { Prescribed }\end{array}$ & $\begin{array}{c}\text { Back for Dry } \\
\text { Socket? }\end{array}$ & \\
\cline { 2 - 5 } & & & & & \\
\end{tabular}

Notes (including change of address): 
Visit \#

\begin{tabular}{|l|c|c|c|c|c|}
\hline Date & Stated Reason & Pain Rating & Diagnosis & \# Teeth (Pan) & $\begin{array}{c}\text { Procedure } \\
\text { (Tooth \#) }\end{array}$ \\
\hline & & & & & \\
\cline { 2 - 5 } & $\begin{array}{c}\text { Local } \\
\text { Anesthetic }\end{array}$ & $\begin{array}{c}\text { Noted } \\
\text { Anxiety }\end{array}$ & $\begin{array}{c}\text { Drugs } \\
\text { Prescribed }\end{array}$ & $\begin{array}{c}\text { Back for Dry } \\
\text { Socket? }\end{array}$ & \\
\cline { 2 - 5 } & & & & & \\
\end{tabular}

Notes (including change of address):

Visit \#

\begin{tabular}{|l|c|c|c|c|c|}
\hline Date & Stated Reason & Pain Rating & Diagnosis & \# Teeth (Pan) & $\begin{array}{c}\text { Procedure } \\
\text { (Tooth \#) }\end{array}$ \\
\hline & & & & & \\
\cline { 2 - 5 } & $\begin{array}{c}\text { Local } \\
\text { Anesthetic }\end{array}$ & $\begin{array}{c}\text { Noted } \\
\text { Anxiety }\end{array}$ & $\begin{array}{c}\text { Drugs } \\
\text { Prescribed }\end{array}$ & $\begin{array}{c}\text { Back for Dry } \\
\text { Socket? }\end{array}$ & \\
\cline { 2 - 5 } & & & & & \\
\end{tabular}

Notes (including change of address): 
Appendix F

Chart Abstraction Summary

Participant name:

Date of study visit:

Current tobacco use: $\mathrm{Y} N$ Previous tobacco use: $\mathrm{Y} \quad \mathrm{N}$

Psychotropic Medications:
ID:

Pan Available: $\mathrm{Y} \quad \mathrm{N}$

Amount:

Mental health concerns:

Previous problems with/during dental care:

MISC:

Appointment/Procedure History:

\begin{tabular}{|c|l|l|}
\hline Cleanings & & \\
\hline Restorations & & \\
\hline Extractions & & \\
\hline Appliance Visits & & \\
\hline Other Procedures & & \\
\hline Total Visits & & \\
\hline Missed Appointments & & \\
\hline
\end{tabular}

Most Recent Visit Date:

Notes about last visit:

Number of Teeth:

Pain Ratings: 